birth of an appreciably handicapped child at the end of a normal pregnancy is about 1 in 30 , so that the additional hazard from diagnostic $x$-ray procedures is small compared with the other hazards. Certainly it would not normally justify an abortion.

Nevertheless, while the chances of a developmental abnormality or handicap due to diagnostic radiology are small compared with the natural incidence of these problems, the same is not true of the much rarer cases of leukaemia or neoplasia in childhood. Again the chance that diagnostic radiology will cause these disorders is extremely small, but should they arise the chance that the previous radiography was the cause will vary according to the dose, but will often be as high as $10-50 \%$.

For many years radiologists, radiographers, and clinicians in general have been urged to avoid irradiation during pregnancy in the absence of an overriding medical necessity of proper care for the mother. Women needing routine diagnostic radiographs are scheduled for the first 10 days from the onset of the menstrual period so that the irradiation is given when there is little chance of the patient being pregnant. (The fact that the maturating ovum is also sensitive lessens the value of this procedure: even when the 10-day rule was observed, in theory the patient should perhaps have been advised not to start a pregnancy deliberately until one or two normal periods have occurred.) If, however, the hazard is less than was previously thought and is small compared with all other natural hazards, too much time and effort need not be spent trying to avoid it. On the other hand, women in general have come to believe that there is a hazard from radiation; so it may still be wiser for doctors to take what steps they can to avoid irradiation during pregnancy, since there will then be no worry about what to do or whether the radiography should have been done at all. Caution may avoid the unnecessary tragedy of a woman worrying for 10 or 20 years whether her child might develop leukaemia or neoplasia.

${ }^{1}$ Mole, R H, British fournal of Radiology, 1979, 52, 89.

\section{Neurodevelopmental handicap in very low birth weight infants}

Babies weighing less than $1500 \mathrm{~g}$ at birth are extremely vulnerable in the perinatal period to respiratory and metabolic disorders, and these account for much of their high mortality rate. The same perinatal problems play an important part in the high incidence of later neurodevelopmental handicap. Better understanding and management of these disorders in specialist centres in Europe and North America have improved neonatal survival and lowered the rates of handicap in these babies of very low birth weight, ${ }^{1-3}$ but its incidence is still unacceptably high. When handicap is defined as the presence of major or minor neurological abnormality, a moderate to severe hearing or visual defect, or an intelligence quotient below 70, it is found in between $18 \%$ and $44 \%$ of babies weighing less than $1500 \mathrm{~g} .{ }^{4}$ Recent studies have highlighted two neonatal problems which are associated with the later recognition of neurodevelopmental handicap in these small babies: neurological abnormality and intrauterine growth retardation. Better understanding of these problems might help to reduce the incidence of adverse sequelae.

Fitzhardinge and her colleagues in Montreal $^{5}$ described the neurodevelopmental state of 149 babies of very low birth weight at roughly 2 years of age. As many as $44(30 \%)$ had major handicaps, at highest risk being those with a history of recurrent neonatal seizures due to intracranial (mainly intraventricular) haemorrhage: neurodevelopmental handicap occurred in 13 out of 15 such babies. Isolated seizures without clinical evidence of intracranial bleeding were not associated with adverse sequelae. At next highest risk were babies with evidence at birth of severe intrauterine growth retardation. Of 40 babies whose birth weights were more than two standard deviations below the expected mean for gestation, 21 were severely handicapped. To determine the effects of intrauterine growth retardation apart from the other complications of preterm delivery 28 such babies of less than 33 weeks' gestation at birth were paired with 28 preterm babies of appropriate weight for gestation and with a similar neonatal course. Twelve of the babies with intrauterine growth retardation were handicapped compared with only three of the others. The affected babies also had significantly lower development scores and were smaller.

Gross and his colleagues ${ }^{6}$ reviewed the growth and development at approximately 5 years of age of 118 babies weighing below $2000 \mathrm{~g}$ at birth, including 41 of very low birth weight. Particular reference was made to small occipitofrontal head circumference (as a measure of intrauterine growth retardation) and abnormal neonatal neurological behaviour. Major and minor neurological defects, low IQ, sensory abnormalities, and smallness in height, weight, and head circumference were all more frequent in babies whose head circumference was below the tenth centile at birth. Furthermore, 13 of the 118 children who had shown abnormal neurological signs in the neonatal period were later found to have more major abnormalities and smallness of their physical dimensions than those with a normal neonatal history.

The poor prognosis of neonatal neurological abnormality shown in these and other studies ${ }^{7}$ is most likely to be due to brain damage from hypoxia originating either in labour or early in postnatal life. The sequelae of severe handicap might be reduced by early recognition of intrapartum asphyxia by fetal monitoring (and prompt intervention); a greater sense of urgency in delivery rooms in establishing respiration in these small infants; and the effective management of hyaline membrane disease and recurrent apnoeic episodes. The poor neurodevelopmental outcome associated with intrauterine growth retardation is harder to explain, though the high incidence reported by Fitzhardinge in poorly grown babies is the highest recorded. Both Fitzhardinge ${ }^{5}$ and Gross ${ }^{6}$ have suggested that the explanation may lie in interference with brain growth by nutritional or other factors, including congenital virus infections and drugs. This explanation is not in keeping, however, with what is known about the pathological changes in the brain associated with intrauterine growth retardation, which results in widespread distortions and deficits of brain structure (such as smaller brain size, reduced concentration of some myelin lipids, and fewer cells ${ }^{8-10}$ ) rather than focal structural damage. Since placental lesions are almost universally present in these infants a more realistic explanation may be that poor fetal growth predisposes to intrapartum asphyxia with consequent brain damage. In Gross's ${ }^{6}$ study a low occipitofrontal circumference at birth was found to be associated with a low five-minute Apgar score, so giving some support to this hypothesis. On the other hand this explanation seems not 
to account for Fitzhardinge's ${ }^{5}$ findings of a direct association of neurodevelopmental handicap with intrauterine growth retardation.

Understanding the mechanism or mechanisms whereby poor intrauterine growth makes infants of very low birth weight at risk of neurodevelopmental handicap extends beyond mere scientific curiosity: there are important clinical implications. If there is direct interference with brain growth obstetricians will be faced with the difficult dilemma of how long intrauterine life should continue once intrauterine growth retardation has been diagnosed. Should elective delivery by caesarean section be seriously considered, and, if so, when? Where there are no maternal contraindications to continuing the pregnancy, should more serious attempts be made to improve fetoplacental function, and therefore intrauterine growth, by treatment with heparin ${ }^{11}$ or hypertonic dextrose and amino-acid solutions ? $^{12}$ On the other hand, if, and as seems more likely, intrapartum asphyxia is the cause of later handicap in these babies then the emphasis must be on the delivery. Every effort must be made for this to take place in a unit where there are facilities for intrapartum monitoring and where the necessary medical skills are available to intervene in labour and to resuscitate the baby promptly should asphyxia have occurred.

${ }^{1}$ Calâme, A, and Prod'hom, L S, Schweizerische medizinische Wochenschrift, $1972,102,65$.

2 Davies, P A, and Tizard, J P M, Developmental Medicine and Child Neurology, 1975, 17, 3.

${ }^{3}$ Stewart, A, et al, in Major Mental Handicap: Methods and Costs of Prevention, Ciba Foundation Symposium 59 (new series), p 139. Elsevier, Excerpta Medica, 1978

4 Davies, P A, in Recent Advances in Paediatrics, no 5, ed D Hull, p 89. Edinburgh, Churchill Livingstone, 1976.

${ }^{5}$ Fitzhardinge, P M, et al, in Major Mental Handicap: Methods and Costs of Prevention, Ciba Foundation Symposium 59 (new series), p 139. Elsevier, Excerpta Medica, 1978.

6 Gross, S J, et al, American fournal of Diseases of Children, 1978, 132, 754

7 Marriage, K, and Davies, P A, Archives of Disease in Childhood, 1977, $52,176$.

${ }^{8}$ Gruenwald, P, Biology of the Neonate, 1963, 5, 215.

9 Chase, H P, et al, Pediatrics, 1972, 50, 403.

10 Dobbing, J, in Scientific Foundations of Paediatrics, ed J A Davis and $\mathrm{J}$ Dobbing, p 565. London, Heinemann, 1974.

11 Bonnar, J, Fournal of Clinical Pathology, 1974, 27, 514.

12 Beischer, N A, Medical fournal of Australia, 1975, 2, 379.

\section{The dilated upper urinary tract}

No aspect of urology has undergone such recent reappraisal as obstruction of the upper urinary tract. The orthodox view, that dilatation of the upper urinary tract in the absence of vesicoureteric reflux was synonymous with obstruction, has now been discarded in the face of convincing evidence that gross dilatation of the ureter or renal pelvis or both may occur in diseases in which no obstruction can be detected. ${ }^{12}$ In many instances this lesson was learnt the hard way from disappointing results of operating on these dilated but non-obstructed systems; occasionally, and worse, the unfortunate outcome of this pursuit of a will-o'-the-wisp was the creation of a real obstruction or even vesicoureteric reflux.

Investigation of disease of the upper urinary tract is centred on intravenous urography, but mistakes will continue to be made if urography alone is thought to be capable of giving all the answers. The urogram gives only a rough guide to renal function; often it cannot distinguish reliably between a large, flabby upper urinary tract and a tense obstructed one. That is not to say that obstruction cannot be diagnosed from a wellexecuted urogram, but simply that in equivocal or difficult cases it may be misleading. The problem is greater in chronic than in acute obstruction.

The search for better methods of diagnosis has led to study of the dynamics in the upper tract, since obstruction implies an impedance to flow or an increase in the pressure within the system to keep the usual flow of urine passing through. This approach has been fruitful: percutaneous studies of pressure and flow (under radiographic control) are now providing reliable and sometimes unexpected findings, and have been especially useful in managing difficult paediatric problems. ${ }^{34}$ These are, however, invasive procedures, so that inevitably departments of nuclear medicine have taken up the challenge of looking for alternatives. O'Reilly et $a l^{5}$ in Manchester believe that obstructed and non-obstructed dilated systems can be distinguished by comparing the renograms in the dehydrated and hydrated states. Nevertheless, they compared their initial results only with their findings at operation. Others who have compared the Manchester method with dynamic studies have found that even renography on hydrated patients can overdiagnose obstruction in those with greatly dilated upper tracts and underdiagnose it in those with early obstruction but minimal dilatation. ${ }^{2}$

A group from St Bartholomew's Hospital has compared three different ways of diagnosing obstruction in patients with equivocal hydronephrosis ${ }^{6}:$ firstly, the increase in size of the renal pelvis on a urogram after the administration of a diuretic; secondly, percutaneous dynamic studies; and, finally, renography. Their numbers were small, and in only 12 of their 20 patients could the results of all three studies be compared. Nevertheless, they contend that there is evidence of obstruction when the patient is given intravenous frusemide and the size of the renal pelvis increases by over a fifth of its size at 20 minutes after injection of contrast medium. The report does not state if any of the pelves collapsed down on an erect or postmicturition film-a sign often taken to indicate the absence of significant obstruction. A critical and longer look at this method is needed.

A new approach that emerged from this and a later study by the same group at St Bartholomew's is using radioactive isotopes to measure the "transit time" between the renal parenchyma and the collecting system. ${ }^{7}$ When obstruction has affected function (obstructive nephropathy) the parenchymal transit time is increased-apparently because increased retention of salt and water prolongs the intratubular luminal transit of the isotope. This method should overcome the problem of poor mixing in a very dilated system, but whether it is measuring obstruction or its subsequent effect on the kidney is not yet clear-for factors other than obstruction could alter the transit time. Nevertheless, undoubtedly after relief of obstruction the transit time returns towards normal.

These elaborate isotope techniques are at an early stage of development, and whether they will provide a reliable answer in all cases of equivocal obstruction remains to be seen. Meanwhile urodynamic techniques remain a standard against which they can be compared.

\footnotetext{
' Shopfner, C E, American fournal of Roentgenology, 1966, 98, 172

2 Whitaker, R H, British fournal of Urology, 1975, 47, 377

${ }^{3}$ Whitaker, R H, British fournal of Urology, 1973, 45, 15.

${ }^{4}$ Whitfield, H N, et al, British fournal of Urology, 1976, 48, 427.

5 O'Reilly, P H, et al, British Fournal of Urology, 1978, 50,76.

6 Whitfield, H N, et al, British fournal of Urology, 1977, 49, 615.

? Whitfield, H N, et al, British fournal of Urology, 1978, 50, 433.
} 